Revista de Comunicación y Salud, 2020, Vol. 10, oㅡ 2, pp. 607-624

Editado por Cátedra de Comunicación y Salud

ISSN: 2173-1675

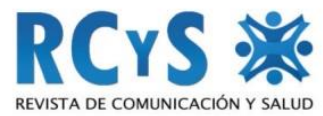

Enviado $15 / 08 / 2020$

Aprobado 23/09/2020

\title{
LA NECESARIA PROTECCIÓN DE LAS CATEGORÍAS ESPECIALES DE DATOS PERSONALES. UNA REFLEXIÓN SOBRE LOS DATOS RELATIVOS A LA SALUD COMO AXIOMA IMPRESCINDIBLE PARA ALCANZAR EL ANHELADO DESARROLLO TECNOLÓGICO FRENTE AL COVID-19
}

\section{The Necessary Protection of Special Categories of Personal Data. A Reflection on Health Data as an Essential Axiom for Achieving the Desired Technological Development in Relation to COVID-19}

\author{
José Luis Domínguez Álvarez ${ }^{1}$ \\ Universidad de Salamanca. España. \\ jldoal@usal.es
}

Financiación. La presente contribución se realiza al amparo del Programa de Ayudas para la Formación de Profesorado Universitario (FPU17/01088) del Ministerio de Educación, Cultura y Deporte. El autor es miembro del Grupo de Investigación Reconocido "Reforma y Modernización de las Administraciones Públicas" (GISALMAD-USAL).

\section{Resumen}

La irrupción del COVID-19 ha propiciado el surgimiento de multitud de transformaciones de profundo calado, las cuales rebasan la esfera puramente sanitaria, propiciando importantes cambios socioeconómicos, entre los que destaca por su extraordinaria importancia la evolución de las formas tradicionales de intervención administrativa o el empoderamiento y/o aceleración de los avances derivados de la (re)volución digital. De esta forma, en los últimos meses hemos asistido a la implementación de numerosas iniciativas encaminadas a paliar los efectos nocivos de la pandemia sanitaria mediante el desarrollo de herramientas tecnológicas sustentadas en el tratamiento de categorías de datos personales especialmente protegidos, como son los datos relativos a la salud, lo que plantea importantes incógnitas desde la perspectiva de la privacidad y los derechos digitales. El presente estudio tiene por objeto realizar un análisis pormenorizado de las cuestiones esenciales necesarias para alcanzar el difícil equilibrio entre el impulso de instrumentos tecnológicos que contribuyan a controlar los efectos del COVID-19, incrementando los recursos a disposición de las autoridades sanitarias, y la salvaguarda del derecho fundamental a la protección de datos de carácter personal.

1 José Luis Domínguez Álvarez: Personal Investigador en Formación (FPU) del Área de Derecho Administrativo de la Universidad de Salamanca, especializado en el estudio de la protección de datos de carácter personal ante la (re)volución digital, la modernización de las Administraciones públicas, el desarrollo rural sostenible y la España vaciada, así como en la implementación de políticas públicas de igualdad y lucha contra la violencia de género. 
La necesaria protección de las categorías especiales de datos personales. Una reflexión sobre los datos relativos a la salud como axioma imprescindible para alcanzar el anhelado desarrollo tecnológico frente al COVID-19

Palabras clave: COVID-19, protección de datos personales, privacidad, desarrollo tecnológico, autoridades sanitarias, Radar COVID.

\begin{abstract}
The irruption of COVID-19 has led to a multitude of deep-seated transformations, which go beyond the purely sanitary sphere, leading to major socio-economic changes, among which the evolution of traditional forms of administrative intervention or the empowerment and/or acceleration of the advances derived from the digital (re)volution stand out for their extraordinary importance. Thereby, in recent months we have witnessed the implementation of numerous initiatives aimed to alleviate the harmful effects of the pandemic by developing technological tools based on processing categories of specially protected personal data, such as health data, which raises important questions from the perspective of privacy and digital rights. The aim of this study is to carry out a detailed analysis of some essential elements, necessary to achieve the difficult balance between the promotion of technological instruments that contribute to control the effects of COVID-19 increasing the resources available to health authorities, and safeguarding the fundamental right of personal data protection.
\end{abstract}

Keywords: COVID-19, protection data, privacy, technological development, health authorities, Radar COVID.

\title{
Cómo citar el artículo
}

Domínguez Álvarez, J. L. (2020). La necesaria protección de las categorías especiales de datos personales. Una reflexión sobre los datos relativos a la salud como axioma imprescindible para alcanzar el anhelado desarrollo tecnológico frente al COVID-19. Revista de Comunicación y Salud, 10 (2), 607-624. doi: https://doi.org/10.35669/rcys.2020.10(2).607-624

\section{INTRODUCCIÓN}

A finales del pasado año, apareció en la Provincia de Hubei de la República Popular China un nuevo brote de coronavirus (SARS-CoV-2), causando una enorme conmoción entre la comunidad médica y el resto del mundo (Velavan y Meyer, 2020). Pese a la adopción de multitud de medidas sanitarias y diferentes protocolos el COVID-19 ha terminado por convertirse en una pandemia sin precedentes en nuestra historia reciente, propiciando la saturación de los recursos sanitarios y provocando enormes pérdidas humanas, económicas y sociales (Palacios Cruz, Santos, Velázquez Cervantes y León Juárez, 2020).

El continente europeo, y especialmente nuestro país, no han sido ajenos en forma alguna a los devastadores efectos de la pandemia mundial ${ }^{2}$, cuya crudeza se refleja en

${ }^{2}$ La Organización Mundial de la Salud elevó el pasado 11 de marzo de 2020 la situación de emergencia de salud pública ocasionada por el COVID-19 a pandemia internacional.

Revista de Comunicación y Salud, 2020, Vol. 10, oㅡ 2, pp. 607-624 
La necesaria protección de las categorías especiales de datos personales. Una reflexión sobre los datos relativos a la salud como axioma imprescindible para alcanzar el anhelado desarrollo tecnológico frente al COVID-19

multitud de cifras ${ }^{3}$ que esconden tras de sí dramáticas pérdidas humanas, económicas y sociales.

Como es bien sabido, en los últimos meses las tecnologías y los datos digitales, especialmente en lo que se refiere al procesamiento masivo de datos cuantitativos y cualitativos, han cobrado una importancia transcendental en la lucha contra la crisis del COVID-19 (Martínez Martínez, 2020b). Ciertamente, estas tecnologías y datos ofrecen en muchos casos una herramienta importante para informar al conjunto de la ciudadanía y ayudar a las autoridades públicas pertinentes en sus esfuerzos por contener la propagación del virus o para permitir que las organizaciones sanitarias intercambien datos con celeridad sobre la salud. Sin embargo, como ha puesto de relieve la Comisión Europea en su Recomendación 2020/518 relativa a un conjunto de instrumentos comunes de la Unión para la utilización de la tecnología y los datos a fin de combatir y superar la crisis de la COVID-19 en particular por lo que respecta a las aplicaciones móviles y a la utilización de datos de movilidad anonimizados, un enfoque fragmentado y descoordinado del empleo de nuevas tecnologías basadas en el tratamiento de datos personales pone en peligro la eficacia de las medidas destinadas a combatir la crisis de la COVID-19, dañando gravemente tanto al mercado único como los derechos y libertades fundamentales.

En este sentido, son muchos los esfuerzos destinados por parte de las diferentes Administraciones públicas al diseño de aplicaciones móviles que pueden contribuir al seguimiento y la contención de la actual pandemia sanitaria (Cotino Hueso, 2020) ${ }^{4}$. Animados por las múltiples oportunidades que ofrecen estas herramientas, entre las que destacan la posibilidad de proporcionar orientación a los ciudadanos acerca de las medidas de distanciamiento social, facilitar la organización del seguimiento médico de los pacientes o el rastreo de los contactos, limitando con ello la propagación de la enfermedad e interrumpiendo las cadenas de transmisión; lo cierto es que combinadas con estrategias adecuadas de realización de pruebas PCR y con el seguimiento de los contactos, las aplicaciones pueden ser especialmente importantes a la hora de proporcionar información sobre el nivel de circulación del virus, evaluar la eficacia de las medidas de distanciamiento físico y confinamiento y orientar las estrategias de desescalada para agilizar en la medida de lo posible la tenebrosa tarea de recuperación económica y social que esta por venir.

De esta forma, no resulta difícil encontrar distintas iniciativas públicas y privadas ${ }^{5}$ orientadas a la creación de aplicaciones y recursos web estrechamente relacionados

\footnotetext{
${ }^{3}$ La tasa de detección de casos cambia diariamente y puede seguirse prácticamente en tiempo real en el siguiente sitio web proporcionado por la Universidad Johns Hopkins: https://gisanddata.maps.arcgis.com/apps/opsdashboard/index.html\#/bda7594740fd40299423467b48e9ec f6

${ }^{4}$ Buen ejemplo de ello lo encontramos en la Orden SND/297/2020, de 27 de marzo, por la que se encomienda a la Secretaría de Estado de Digitalización e Inteligencia Artificial, del Ministerio de Asuntos Económicos y Transformación Digital, el desarrollo de diversas actuaciones para la gestión de la crisis sanitaria ocasionada por el COVID-19.

5 Siguiendo esta estela de iniciativas y movimientos en tiempos de COVID-19, y teniendo en consideración el tratamiento de datos personales y, particularmente, los datos relacionados con la salud
} 
La necesaria protección de las categorías especiales de datos personales. Una reflexión sobre los datos relativos a la salud como axioma imprescindible para alcanzar el anhelado desarrollo tecnológico frente al COVID-19

con la pandemia del COVID-19, iniciativas que en la mayor parte de los casos están sustentadas en el tratamiento de datos sanitarios, o lo que es lo mismo, en datos personales especialmente protegidos conforme al art. 9 RGPD. Dentro de estas aplicaciones tecnológicas encontramos dos grandes grupos, en función de su finalidad y tipología: las aplicaciones de alerta y seguimiento; y las aplicaciones de autodiagnóstico y análisis de síntomas.

Independientemente de la tipología de las aplicaciones o herramientas a las que hagamos referencia, lo cierto es que, la implementación de nuevas tecnologías sustentadas en el tratamiento de datos personales, unido al uso de técnicas propias de la analítica de datos e Inteligencia Artificial, comportan importantes beneficios y representan una importante oportunidad para ganar la batalla al COVID-19, en tanto en cuanto, permiten mejorar la capacidad de previsión y decisión de las autoridades sanitarias, contribuyen a fortalecer la eficacia de las medidas de distanciamiento social, reduciendo con ello significativamente la propagación de la pandemia, o mediante la maximización de la anhelada eficiencia administrativa, idea-fuerza que nuestra Constitución recoge en su art. 103.1 como principio rector de la actuación de las Administraciones públicas, y que hoy más que nunca se hace imprescindible a la hora asignar estratégicamente los medios y recursos sanitarios para minimizar el coste humano, el cual a estas alturas es ya insufrible (Terrón Santos, Domínguez Álvarez, y Fernando Pablo, 2020).

Sin embargo, dadas las funciones de las aplicaciones y herramientas habilitadas para teléfonos inteligentes, descritas anteriormente, su uso es susceptible de afectar al ejercicio de determinados derechos fundamentales ${ }^{6}$ como el derecho al respeto de la

que muchas de estas iniciativas implican, la Agencia Española de Protección de Datos (AEPD) emitió, el pasado 26 de marzo, un comunicado sobre los criterios que permiten compatibilizar el uso de estas apps y web de autoevaluación de COVID-19 con la regulación existente en materia de protección de datos. Conforme a las indicaciones facilitadas por la AEPD, "únicamente podrán tratar dichos datos las autoridades públicas competentes para actuar conforme a la declaración del estado de alarma, es decir, el Ministerio de Sanidad y las Consejerías de Sanidad de las Comunidades Autónomas, que podrán cederse datos entre ellas, y a los profesionales sanitarios que traten a los pacientes o que intervengan en el control de la epidemia. Las entidades privadas que colaboren con dichas autoridades sólo podrán utilizar los datos conforme a las instrucciones de estas y, en ningún caso, para fines distintos de los autorizados". Comunicado oficial de la AEPD recuperado de: https://www.aepd.es/es/prensa-ycomunicacion/notas-de-prensa/aepd-apps-webs-autoevaluacion-coronavirus-privacidad

${ }_{6}^{6}$ Un buen ejemplo de ello lo encontramos en la aplicación para móviles, promovida por el Gobierno de Pekín, conocida como "Código de salud», herramienta que fue distribuida en las populares plataformas Alipay y WeChat para proceder a la recopilación de enormes cantidades de datos relativos a la movilidad y la salud de la ciudadanía -lejos de los principios que deben informar todo tratamiento de datos personales en el continente europeo- - Esta herramienta permite asignar un color identificativo a cada persona, en función de los datos introducidos por el propio individuo. Este código (verde, amarillo o rojo) determina la movilidad del individuo, y puede ser requerido para su comprobación por las autoridades en la vía pública, en los accesos a los establecimientos comerciales o en el transporte público. Según los expertos, esta aplicación ha desarrollado un papel crucial a la hora de reducir considerablemente la expansión de la pandemia en el gigante asiático, renunciando eso sí a la privacidad del conjunto de la sociedad, algo extremadamente peligroso en las turbulentas aguas del mundo de la digitalización y datificación. 
La necesaria protección de las categorías especiales de datos personales. Una reflexión sobre los datos relativos a la salud como axioma imprescindible para alcanzar el anhelado desarrollo tecnológico frente al COVID-19

vida privada y familiar o el derecho a la protección de datos de carácter personal, entre otros (Martínez Martínez, 2020a). En las próximas páginas se analizan una serie de cuestiones esenciales necesarias para alcanzar el difícil equilibrio entre el impulso de instrumentos tecnológicos que contribuyan a controlar los efectos del COVID-19, incrementando los recursos a disposición de las autoridades sanitarias, y la salvaguarda del derecho fundamental a la protección de datos de carácter personal.

\section{OBJETIVOS}

El presente estudio tiene como finalidad despejar, sobre la base y las premisas del viejo Estado de Derecho, las principales incógnitas que rodean el empleo de la tecnología en tiempos de zozobra, contribuyendo a clarificar el difícil equilibrio entre desarrollo tecnológico y garantía de los derechos fundamentales de la ciudadanía, prestando especial atención a la protección de datos de carácter personal. Sin perder de vista la finalidad última de esta garantía jurídica, la cual ha sido concebida por la Unión Europea con una fuerte inspiración humanística, tal y como manifiesta lapidariamente el considerando cuarto del Reglamento (UE) 2016/679 del Parlamento Europeo y del Consejo, de 27 de abril de 2016 (Reglamento General de Protección de Datos), «el tratamiento de los datos personales debe ser diseñado para servir a la humanidad».

\section{LA REGULACIÓN DE LA PROTECCIÓN DE DATOS PERSONALES DE CARÁCTER SANITARIO: POSIBILIDADES PARA SU CORRECTO TRATAMIENTO}

Como se ha puesto de manifiesto por numerosos teóricos y académicos, la declaración del estado de alarma decretada tras la adopción del Real Decreto 463/2020, de 14 de marzo, no permite limitar derechos y libertades más allá de lo que dispone el citado artículo 11 de la Ley Orgánica 4/1981 (Lozano Cutanda, 2020; Fernández de Gatta Sánchez, 2020), lo que habida cuenta tiene una serie de implicaciones desde el punto de vista de la protección de datos de carácter personal.

Con carácter general, tanto el Comité Europeo de Protección de Datos ${ }^{7}$ como las diferentes Autoridades de control (Piñar Mañas, 2020b), entre ellas la AEPD, han hecho

7 Así, el Comité Europeo de Protección de Datos en su declaración sobre el tratamiento de datos personales en el contexto de la crisis del Covid-19, de 16 de marzo, establece la ausencia de impedimentos por parte de la normativa sobre protección de para proceder a la lucha contra la pandemia del coronavirus, al señalar que: "the GDPR is a broad legislation and also provides for the rules to apply to the processing of personal data in a context such as the one relating to COVID-19. Indeed, the GDPR provides for the legal grounds to enable the employers and the competent public health authorities to process personal data in the context of epidemics, without the need to obtain the consent of the data subject. This applies for instance when the processing of personal data is necessary for the employers for reasons of public interest in the area of public health or to protect vital interests (Art. 6 and 9 of the GDPR) or to comply with another legal obligation. For the processing of electronic communication data, such as mobile location data, additional rules apply. The national laws implementing the ePrivacy Directive provide for the principle that the location data can only be used by the operator when they are made anonymous, or with the consent of the individuals. The public authorities should first aim for the processing of location data in an anonymous way (i.e. processing data aggregated in a way that it cannot be reversed to

Revista de Comunicación y Salud, 2020, Vol. 10, nº 2, pp. 607-624 
La necesaria protección de las categorías especiales de datos personales. Una reflexión sobre los datos relativos a la salud como axioma imprescindible para alcanzar el anhelado desarrollo tecnológico frente al COVID-19

públicas sendas declaraciones en relación con el tratamiento de datos personales en el contexto de la crisis del Covid-19. Todos estos pronunciamientos manifiestan un sentir común, al resaltar que la normativa sobre protección de datos y en particular el Reglamento (UE) 2016/679, no impiden tomar medidas en la lucha contra la pandemia del coronavirus, pero advierten que incluso en estas excepcionales circunstancias quienes traten datos personales deben asegurar su protección, más si tenemos en cuenta que en muchos casos dichos tratamientos utilizan datos especialmente sensibles, como son los datos relacionados con la salud, los cuales están íntima y estrechamente ligados con el derecho a la vida (Troncoso Reigada, 2010).

Conforme a la regulación actual, los datos relativos a la salud representan lo que se conoce como categorías especiales de datos personales. Conviene recordar que el RGPD califica como tales a aquellos datos que "por su naturaleza, son particularmente sensibles en relación con los derechos y las libertades fundamentales" (Considerando 51). Y el apartado primero del artículo 9 RGPD mantiene en lo esencial los datos que ya se consideraban merecedores de una mayor protección en el artículo 8 de la Directiva 95/46/CE: origen étnico o racial; opiniones políticas; convicciones religiosas o filosóficas; afiliación sindical; salud y sexualidad, aunque en lo concerniente a este último ahora se precisa: "datos relativos a la vida sexual o a las orientaciones sexuales" (Medina Guerrero, 2019).

Por su parte, el art. 4.15) RGPD concreta y clarifica el concepto "datos relativos a la salud", a diferencia de la Directiva 95/46/CE, que no abordaba su conceptuación. En virtud de dicho precepto, se entiende por datos relativos a la salud aquellos "datos personales relativos a la salud física o mental de una persona física, incluida la prestación de servicios de atención sanitaria, que revelen información sobre su estado de salud".

Precisado lo anterior, conviene clarificar el régimen jurídico y las posibilidades de tratamiento de estos datos sanitarios, los cuales como hemos revelado son fundamentales para propiciar el desarrollo tecnológico suficiente y necesario para ganarle la partida al COVID-19.

En este sentido, lo primero que tenemos que señalar es que el propio RGPD, en su considerando 46, reconoce que, en situaciones excepcionales, como la que vivimos en el presente momento, la base jurídica de los tratamientos puede ser múltiple, basada tanto en el interés público, como en el interés vital del interesado u otra persona física.

personal data). This could enable to generate reports on the concentration of mobile devices at a certain location ("cartography"). When it is not possible to only process anonymous data, Art. 15 of the ePrivacy Directive enables the member states to introduce legislative measures pursuing national security and public security. This emergency legislation is possible under the condition that it constitutes a necessary, appropriate and proportionate measure within a democratic society. If such measures are introduced, a Member State is obliged to put in place adequate safeguards, such as granting individuals the right to judicial remedy".

Revista de Comunicación y Salud, 2020, Vol. 10, nº 2, pp. 607-624 
La necesaria protección de las categorías especiales de datos personales. Una reflexión sobre los datos relativos a la salud como axioma imprescindible para alcanzar el anhelado desarrollo tecnológico frente al COVID-19

(46) "El tratamiento de datos personales también debe considerarse lícito cuando sea necesario para proteger un interés esencial para la vida del interesado o la de otra persona física. En principio, los datos personales únicamente deben tratarse sobre la base del interés vital de otra persona física cuando el tratamiento no pueda basarse manifiestamente en una base jurídica diferente. Ciertos tipos de tratamiento pueden responder tanto a motivos importantes de interés público como a los intereses vitales del interesado, como por ejemplo cuando el tratamiento es necesario para fines humanitarios, incluido el control de epidemias y su propagación, o en situaciones de emergencia humanitaria, sobre todo en caso de catástrofes naturales o de origen humano".

Por lo tanto, como base jurídica para un tratamiento lícito de datos personales (Puyol Montero, 2016), sin perjuicio de que puedan existir otras bases, como por ejemplo, el cumplimiento de una obligación legal ex art. 6.1.c) RGPD, como pueden ser aquellos tratamientos de datos personales desarrollados por el empleador en materia de prevención de riesgos laborales de sus empleados; el RGPD reconoce explícitamente dos bases jurídicas legitimadoras ${ }^{8}$ del tratamiento de datos personales diferenciadas: el tratamiento es necesario para proteger intereses vitales del interesado o de otra persona física -art. 6.1.d)—; y el tratamiento es necesario para el cumplimiento de una misión realizada en interés público o en el ejercicio de poderes públicos conferidos al responsable del tratamiento -art. 6.1.e)-.

El art. 6.1, letra d) RGPD considera no solo que el interés vital es suficiente base jurídica del tratamiento para proteger al interesado ${ }^{9}$, sino que dicha base jurídica puede ser utilizada para proteger los intereses vitales "de otra persona física", lo que por extensión supone que dichas personas físicas pueden ser incluso no identificadas 0 identificables; es decir, dicha base jurídica del tratamiento —el interés vital- puede ser suficiente para los tratamientos de datos personales dirigidos a proteger a todas aquellas personas susceptibles de ser contagiadas en la propagación de una epidemia, lo que justificaría, desde el punto de vista de tratamiento de datos personales, en la manera más amplia posible, las medidas adoptadas a dicho fin, incluso aunque se dirijan a proteger personas innominadas o en principio no identificadas o identificables, por cuanto los intereses vitales de dichas personas físicas habrán de ser salvaguardados, y ello es reconocido por la normativa de protección de datos personales (Agencia Española de Protección de Datos, 2020).

Sentado lo anterior, no parece extraño que esta base jurídica del tratamiento, se haya vinculado tradicionalmente a la establecida en el artículo $9.2 \mathrm{c}$ ) del RGPD, en tanto en cuanto permite levantar la prohibición de tratamiento de las categorías

\footnotetext{
${ }^{8}$ De conformidad con el considerando 40 RGPD, «para que el tratamiento sea lícito, los datos personales deben ser tratados con el consentimiento del interesado o sobre alguna otra base legítima establecida conforme a Derecho, ya sea en el presente Reglamento o en virtud de otro Derecho de la Unión o de los Estados miembros a que se refiera el presente Reglamento [...]»

9 En virtud del art. 4.1) RGPD, debemos entender por interesado toda persona física identificada 0 identificable.
} 
La necesaria protección de las categorías especiales de datos personales. Una reflexión sobre los datos relativos a la salud como axioma imprescindible para alcanzar el anhelado desarrollo tecnológico frente al COVID-19

especiales de datos reguladas por el mismo cuando el tratamiento es necesario para proteger intereses vitales del interesado o de otra persona física, en el supuesto de que el interesado no esté capacitado, física o jurídicamente, para dar su consentimiento (Puente Escobar, 2019).

Sin embargo, para el tratamiento de datos relacionados con la salud no basta con que exista una base jurídica del art. 6 RGPD, sino que de acuerdo con el art. 9.1 y 9.2 RGPD debe existir necesariamente una circunstancia que levante la prohibición de tratamiento de dicha categoría especial de datos (Martínez Martínez, 2020ª).

En el caso concreto en el que nos encontramos, estas circunstancias conviene buscarlas en varios de los apartados reseñados en el art. 9.2 RGPD. Así, la prohibición de proceder al tratamiento de datos personales relacionados con la salud no operará en los siguientes casos:

Primero, a tenor de lo establecido en la letra b) del citado precepto, cuando el tratamiento sea necesario para el cumplimiento de obligaciones y el ejercicio de derechos específicos del responsable del tratamiento o del interesado en el ámbito del Derecho laboral y de la seguridad y protección social, en la medida en que así lo autorice el Derecho de la Unión de los Estados miembros o un convenio colectivo con arreglo al Derecho de los Estados miembros que establezca garantías adecuadas del respeto de los derechos fundamentales y de los intereses del interesado.

Segundo, conforme al art. 9.2.g) RGPD, cuando el tratamiento sea necesario por razones de interés público esencial, sobre la base del Derecho de la Unión o de los Estados miembros, que debe ser proporcional al objetivo perseguido, respetar en lo esencial el derecho a la protección de datos y establecer medidas adecuadas y específicas para proteger los intereses y derechos fundamentales del interesado.

Tercero, en virtud de lo señalado en la letra i), cuando el tratamiento de este conjunto de datos especialmente sensibles sea necesario por razones de interés público en el ámbito de la salud pública, como la protección frente a amenazas transfronterizas graves para la salud, o para garantizar elevados niveles de calidad y de seguridad de la asistencia sanitaria y de los medicamentos o productos sanitarios, sobre la base del Derecho de la Unión o de los Estados miembros que establezca medidas adecuadas y específicas para proteger los derechos y libertades del interesado, en particular el secreto profesional.

Cuarto, y al hilo de lo preceptuado en la letra $\mathrm{h}$ ), cuando el tratamiento sea necesario para realizar un diagnóstico médico, o evaluación de la capacidad de laboral del trabajador o cualquier otro tipo de asistencia de tipo sanitario o para la gestión de los sistemas y servicios de asistencia sanitaria y social.

A estas excepciones, la AEPD considera necesario añadir una quinta y última circunstancia de cierre que permitiría el tratamiento de datos relacionados con la salud. 
La necesaria protección de las categorías especiales de datos personales. Una reflexión sobre los datos relativos a la salud como axioma imprescindible para alcanzar el anhelado desarrollo tecnológico frente al COVID-19

De esta forma, según el criterio de la Agencia "podría ser incluso la establecida en la letra c), en el caso de que se den las circunstancias previstas en este apartado, que aplicaría cuando el tratamiento es necesario para proteger intereses vitales del interesado o de otra persona física, en el supuesto de que el interesado no esté capacitado, física o jurídicamente, para dar su consentimiento" (Agencia Española de Protección de Datos, 2020).

En consecuencia, en una situación de emergencia sanitaria como en la que nos encontramos, es preciso tener en cuenta que, en el exclusivo ámbito de la normativa de protección de datos personales, la aplicación de la normativa de protección de datos personales permitiría adoptar al responsable del tratamiento aquellas decisiones que sean necesarias para salvaguardar los intereses vitales de las personas físicas, el cumplimiento de obligaciones legales o la salvaguardia de intereses esenciales en el ámbito de la salud pública, siempre y cuando se respete el contenido esencial del derecho a la protección de datos y se establezcan las medidas adecuadas ${ }^{10}$ y específicas para proteger los intereses y derechos fundamentales del interesado (Piñar Mañas, 2020ํㅜ).

En este sentido, los responsables del tratamiento, en aras de garantizar su correcta actuación y salvaguardar de forma efectiva los intereses vitales de la ciudadanía, deberán actuar conforme a las instrucciones facilitadas por las autoridades sanitarias, en virtud de lo establecido en las disposiciones normativas sectoriales a tal efecto.

Justamente, conviene señalar que nuestro - denostado por algunos- ordenamiento jurídico, establece una serie de disposiciones legales, necesarias y oportunas para hacer frente a situaciones de riesgo sanitario como el escenario provocado por la irrupción del COVID-19. Nos estamos refiriendo, como no podía ser de otra manera, a la Ley Orgánica 3/1986, de 14 de abril, de Medidas Especiales en Materia de Salud Pública (modificada mediante Real Decreto-ley 6/2020, de 10 de marzo, por el que se adoptan determinadas medidas urgentes en el ámbito económico y para la protección de la salud pública, publicado en el Boletín Oficial del Estado de 11 de marzo de 2020) y a la Ley 33/2011, de 4 de octubre, General de Salud Pública.

A este respecto, el art. 3 de la LO 3/1986, establece que:

"[c]on el fin de controlar las enfermedades transmisibles, la autoridad sanitaria, además de realizar las acciones preventivas generales, podrá adoptar las medidas oportunas para el control de los enfermos, de las personas que estén o hayan estado

10 Atendiendo al principio de responsabilidad proactiva - art. 5.2 RGPD-, y a los principios de protección de datos desde el diseño y por defecto - art. 25 RGPD—, deberán adoptarse, tanto en el momento de determinar los medios de tratamiento como en el momento del propio tratamiento, medidas técnicas y organizativas apropiadas, como la seudonimización, e incluso la agregación y anonimización de los datos relacionados con la salud. Además, conforme al principio de minimización de datos —art. 5.1.c) RGPD—, deberá garantizarse que, por defecto, solo sean objeto de tratamiento los datos personales que sean necesarios para cada uno de los fines específicos del tratamiento y que no serán accesibles, sin intervención de la persona, a un número indeterminado de personas.

Revista de Comunicación y Salud, 2020, Vol. 10, nº 2, pp. 607-624 
La necesaria protección de las categorías especiales de datos personales. Una reflexión sobre los datos relativos a la salud como axioma imprescindible para alcanzar el anhelado desarrollo tecnológico frente al COVID-19

en contacto con los mismos y del medio ambiente inmediato, así como las que se consideren necesarias en caso de riesgo de carácter transmisible".

Por su parte, el art. 54.1 de la Ley 33/2011, de 4 de octubre, General de Salud Pública (LGSP), establece lo siguiente:

"[s]in perjuicio de las medidas previstas en la Ley Orgánica 3/1986, de 14 de abril, de Medidas Especiales en Materia de Salud Pública, con carácter excepcional y cuando así lo requieran motivos de extraordinaria gravedad o urgencia, la Administración General del Estado y las de las comunidades autónomas y ciudades de Ceuta y Melilla, en el ámbito de sus respectivas competencias, podrán adoptar cuantas medidas ${ }^{11}$ sean necesarias para asegurar el cumplimiento de la ley".

Por lo tanto, en materia de enfermedades transmisibles, la normativa sectorial sanitaria anteriormente relacionada otorga a las autoridades sanitarias las competencias necesarias para adoptar las medidas necesarias previstas en dichas leyes cuando así lo exijan razones sanitarias de urgencia o necesidad.

En consecuencia, desde el punto de vista del tratamiento de datos personales, la salvaguardia de los intereses esenciales en el ámbito de la salud pública corresponde a las distintas autoridades sanitarias de las diferentes Administraciones públicas, quienes podrán adoptar las medidas necesarias para salvaguardar dichos intereses esenciales públicos en situaciones de emergencia sanitaria de salud pública.

De este modo, serán estas mismas autoridades sanitarias las encargadas de velar por el correcto tratamiento de los datos personales, conforme a las exigencias y obligaciones establecidas en la normativa de protección de datos de carácter personal. Especialmente en lo que se refiere al estricto cumplimiento de los principios enunciados en el art. 5 RGPD, y entre ellos el de tratamiento de los datos personales con licitud, lealtad y transparencia, de limitación de la finalidad ${ }^{12}$ (en este caso, salvaguardar los

${ }^{11}$ De esta forma, según el criterio del legislador, en virtud del art. 54.2 LGSP, "la autoridad competente podrá adoptar, mediante resolución motivada, las siguientes medidas: a) La inmovilización y, si procede, el decomiso de productos y sustancias; b) La intervención de medios materiales o personales; c) El cierre preventivo de las instalaciones, establecimientos, servicios e industrias. d) La suspensión del ejercicio de actividades; e) La determinación de condiciones previas en cualquier fase de la fabricación 0 comercialización de productos y sustancias, así como del funcionamiento de las instalaciones, establecimientos, servicios e industrias a que se refiere esta ley, con la finalidad de corregir las deficiencias detectadas; f) Cualquier otra medida ajustada a la legalidad vigente si existen indicios racionales de riesgo para la salud incluida la suspensión de actuaciones de acuerdo a lo establecido en el Título II de esta ley".

${ }^{12}$ El considerando 54 RGPD es claro a este respecto: "el tratamiento de categorías especiales de datos personales, sin el consentimiento del interesado, puede ser necesario por razones de interés público en el ámbito de la salud pública. Ese tratamiento debe estar sujeto a medidas adecuadas y especificas a fin de proteger los derechos y libertades de las personas físicas. En ese contexto, «salud pública» debe interpretarse en la definición del Reglamento (CE) núm. 1338/2008 del Parlamento Europeo y del Consejo, es decir, todos los elementos relacionados con la salud, concretamente el estado de salud, con inclusión de la morbilidad y la discapacidad, los determinantes que influyen en dicho estado de salud, las necesidades de asistencia sanitaria, los recursos asignados a la asistencia sanitaria, la puesta a

Revista de Comunicación y Salud, 2020, Vol. 10, oㅡ 2, pp. 607-624 
La necesaria protección de las categorías especiales de datos personales. Una reflexión sobre los datos relativos a la salud como axioma imprescindible para alcanzar el anhelado desarrollo tecnológico frente al COVID-19

intereses vitales/esenciales de las personas físicas), principio de exactitud, y por supuesto, y hay que hacer especial hincapié en ello, el principio de minimización de datos, cuya importancia ya se ha referenciado con anterioridad, garantizando que los datos tratados serán exclusivamente los necesarios para la finalidad pretendida, sin que se pueda extender dicho tratamiento a cualesquiera otros datos personales no estrictamente necesarios para dicha finalidad, sin que pueda confundirse conveniencia con necesidad, porque el derecho fundamental a la protección de datos sigue aplicándose con normalidad, sin perjuicio de que, como se ha dicho, la propia normativa de protección de datos personales establece que en situaciones de emergencia, para la protección de intereses esenciales de salud pública y/o vitales de las personas físicas, podrán tratarse los datos de salud necesarios para evitar la propagación de la enfermedad que ha causado la emergencia sanitaria (Agencia Española de Protección de Datos, 2020).

\section{4. "RADAR COVID", LA APUESTA ESPAÑOLA PARA FRENAR LA EXPANSIÓN DE LA PANDEMIA Y SALVAGUARDAR LOS DERECHOS DE LA PRIVACIDAD DE LA CIUDADANÍA}

Como hemos apuntado con anterioridad, son muchos los esfuerzos que las diferentes Administraciones públicas han desarrollado en los últimos meses para buscar soluciones innovadoras que contribuyeran, por un lado, a incrementar los recursos puestos a disposición del sistema de salud pública, y por otro, a intentar controlar la enorme y rápida expansión de la pandemia, los cuales lejos de disminuir a medida que avanzan las medidas de desescalada amenazan con provocar una segunda oleada de contagios más cruenta que la anterior si cabe. Es en este contexto en el que se enmarcan las labores de impulso e implementación de la app Radar COVID, la cual, pese a su tardía puesta en marcha, se encuentra plenamente operativa en numerosas Comunidades Autónomas de la geografía española, entre las que se encuentran Andalucía, Cantabria, Aragón, Canarias, Extremadura, Baleares y Castilla y León.

En las próximas líneas se analizan las principales ventajas y potencialidades que presenta esta novedosa herramienta, con la finalidad de mejorar y profundizar en el conocimiento de la misma por parte de la ciudadanía, elemento esencial para garantizar su plena eficacia.

\section{1. ¿Qué es Radar COVID?}

Radar COVID es una aplicación para dispositivos móviles de alerta de contagios del virus SARS-CoV-2 desarrollada por el Gobierno de España, cuyo Titular es la Secretaría General de Administración Digital, dependiente de la Secretaría de Estado

disposición de asistencia sanitaria y el acceso universal a ella, así como los gastos y la financiación de la asistencia sanitaria, y las causas de mortalidad. Este tratamiento de datos relativos a la salud por razones de interés público no debe dar lugar a que terceros, como empresarios, compañías de seguros o entidades bancarias, traten los datos personales con otros fines".

Revista de Comunicación y Salud, 2020, Vol. 10, oㅡ 2, pp. 607-624 
La necesaria protección de las categorías especiales de datos personales. Una reflexión sobre los datos relativos a la salud como axioma imprescindible para alcanzar el anhelado desarrollo tecnológico frente al COVID-19

de Digitalización e Inteligencia Artificial del Ministerio de Asuntos Económicos y Transformación Digital.

Gracias a este novedoso instrumento, aquellos usuarios que se hayan descargado la aplicación y acepten su uso recibirán una notificación en caso de que en los catorce días anteriores a esa notificación hayan estado expuestos a un contacto epidemiológico - a menos de dos metros y más de 15 minutos - con otro usuario - totalmente anónimo - que haya declarado en la aplicación haber dado un resultado positivo en la prueba de COVID-19, previa acreditación por parte de las autoridades sanitarias correspondientes. Dicha herramienta informará a los usuarios exclusivamente sobre el día, dentro de los catorce días anteriores, en que se haya producido la exposición al virus, salvaguardando la identidad del usuario al que haya quedado expuesto y protegiendo la identificación del dispositivo de este. De esta forma se ha conseguido articular una herramienta digital que permite maximizar exponencialmente la capacidad de rastreo de propagación del virus de las autoridades sanitarias al tiempo que se establecen elevados estándares de protección de la privacidad, ya que la aplicación no solicita, utiliza ni almacena datos de carácter personal de los usuarios, tal y como se desprende tanto de su política de privacidad como de las afirmaciones de los responsables de dicha herramienta digital.

En este punto, conviene subrayar que el éxito de la citada aplicación como herramienta decisiva orientada a contribuir de manera significativa en las labores de contención de la propagación del virus está directamente vinculado al grado de utilización de la misma por parte de la población, de ahí la necesidad de promover la concienciación de la ciudadanía para maximizar el alcance e impacto de una herramienta tecnológica respetuosa con los derechos fundamentales y que se erige como un arma crucial para paliar los perniciosos efectos de la segunda oleada de la pandemia que está por llegar, labor no exenta de dificultad en la que tanto los medios como los profesionales de la comunicación pueden y deber jugar una labor fundamental.

\section{2. ¿Cómo funciona Radar COVID?}

Una de las principales potencialidades de la app española de lucha contra el COVID19 , es su sencillo e intuitivo diseño. Una vez que el usuario ha procedido a realizar la descarga de la aplicación, ya sea en la App Store o en Google Play dependiendo del sistema operativo del dispositivo, haya aceptado las condiciones de uso y la política de privacidad y comience a utilizarla, el dispositivo móvil generará cada día un identificador pseudo-aleatorio conocido como "clave de exposición temporal" con un tamaño de 16 caracteres (16 bytes o 128 bits) que servirá para derivar los "identificadores efímeros Bluetooth" que son intercambiados con otros teléfonos móviles próximos que también tengan descargada la aplicación Radar COVID.

Ahora bien, ¿qué son los llamados "identificadores efímeros Bluetooth" sobre los que se sustenta la citada app? Dichos identificadores son una serie de códigos pseudo- 
La necesaria protección de las categorías especiales de datos personales. Una reflexión sobre los datos relativos a la salud como axioma imprescindible para alcanzar el anhelado desarrollo tecnológico frente al COVID-19

aleatorios con un tamaño de 16 caracteres (16 bytes, o 128 bits), que se generan por cada uno de los diferentes dispositivos móviles cada 10-20 minutos, a partir de la "clave de exposición temporal" diaria. Lo más relevante de estos códigos es que los mismos no contienen ningún tipo de información personal, que permita identificar directa o indirectamente al dispositivo o al usuario del mismo, protegiendo con ello los datos relativos a la salud de los pacientes en todo momento, lo que convierte a esta herramienta digital en un mecanismo eficaz para ampliar la capacidad de rastreo de las autoridades sanitarias en lo que se refiere a la propagación del virus, al tiempo que se erige como un instrumento respetuoso para con los derechos fundamentales de la ciudadanía, y muy especialmente en lo que atañe a nuestro objeto de estudio, la protección de datos de carácter personal.

Adicionalmente, es necesario conocer que estos "identificadores efímeros Bluetooth" son transmitidos por los smartphones varias veces por segundo a los dispositivos cercanos, accesibles a través de la tecnología Bluetooth Low Energy, produciendo un intercambio de códigos aleatorios entre dispositivos para que puedan ser almacenados por teléfonos próximos que hayan descargado la aplicación. Todo ello con la finalidad de calcular si el usuario ha estado en contacto con alguna persona que haya resultado contagiada por COVID-19 a lo largo de los últimos 14 días.

De igual forma, Radar COVID contempla la posibilidad de comunicar a través de la citada herramienta la recepción de un diagnóstico positivo por COVID-19, mediante la introducción voluntaria en la aplicación del "código de confirmación de un solo uso" que será facilitará previamente por el Servicio Público de Salud y que será validado en el servidor de la app. Posteriormente, la aplicación solicitará el consentimiento expreso del usuario para remitir al servidor las 14 últimas claves de exposición temporal almacenadas en el dispositivo en cuestión, las cuales servirán para componer un listado diario de claves de exposición temporal de personas contagiadas por COVID-19 que serán descargados diariamente desde el servidor por todas las aplicaciones Radar COVID que estén en funcionamiento para garantizar la plena eficacia del producto tecnológico. Es decir, la aplicación descarga periódicamente las claves de exposición temporal compartidas voluntariamente por los usuarios diagnosticados por COVID-19 del servidor, para compararlas con los códigos aleatorios registrados en los días anteriores como resultado de contactos con otros usuarios. Si se encuentra una coincidencia, la aplicación ejecuta un algoritmo en el dispositivo que, en función de la duración y la distancia estimada del contacto, y de acuerdo con los criterios establecidos por las autoridades sanitarias, decide si se muestra una notificación en el dispositivo del usuario expuesto al riesgo de contagio, advirtiéndole del contacto, comunicándole la fecha del mismo e invitándolo a auto-confinarse, y contactar con las autoridades sanitarias.

Es en esta fase donde los medios y profesionales de comunicación adquieren una importancia capital, a la hora de informar a la población sobre las ventajas y potencialidades derivadas de hacer un uso responsable y completo de la aplicación Radar COVID. Y es que, si bien es cierto que las autoridades sanitarias insisten de 
La necesaria protección de las categorías especiales de datos personales. Una reflexión sobre los datos relativos a la salud como axioma imprescindible para alcanzar el anhelado desarrollo tecnológico frente al COVID-19

forma continuada en la necesidad de maximizar la descarga e instalación de la aplicación en el mayor número de terminales móviles posible, esta actuación representa simplemente una de las acciones que como ciudadanos podemos desarrollar para emplear correctamente la herramienta y contribuir así a facilitar las labores de rastreo y control de la expansión de la pandemia. En este sentido, igual o mayor importancia posee emplear la función de comunicar un diagnóstico positivo tras someterse a la preceptiva prueba consignada por las autoridades sanitarias, ya que solamente de esta forma se consigue maximizar la eficacia de la aplicación digital, y con ello el despliegue de las múltiples ventajas derivadas de su implementación.

En definitiva, la app Radar COVID es un instrumento adicional orientado a ampliar los recursos de los que dispone el sistema público de salud para hacer frente a un reto sanitario de proporciones desconocidas, cuyo éxito depende en gran medida de la respuesta que la ciudadanía otorgue a la hora de realizar un uso responsable y completo de las funciones articuladas por las autoridades sanitarias, cuestión esta última que depende de la difusión e información que las Administraciones públicas y los medios de comunicación pongan a disposición de la población.

\section{CONCLUSIONES}

El vertiginoso desarrollo tecnológico se presenta en nuestros días como una herramienta poderosa, capaz de contribuir significativamente en los complejos procesos de toma de decisión por parte de las autoridades sanitarias encaminados a superar la situación de «alarma» provocada por la COVID-19, pandemia que ha provocado unos efectos devastadores, dejando tras de si un doloroso rastro de pérdidas humanas y socioeconómicas, y que ha azotado los pilares de la Unión Europea, llegando incluso a poner en duda los propios valores inherentes al concepto de ciudadanía europea.

Pero más allá de estos efectos demoledores visibles, la COVID-19 ha planteado importantes incógnitas o interrogantes que han propiciado la creación de importantes debates en los que, en múltiples ocasiones, ha llegado a estar en juego la propia vigencia y eficacia del Estado social y democrático de Derecho. Un ejemplo de estos encarnizados debates lo encontramos en la confrontación virulenta que algunos sectores académicos, políticos y sociales han planteado entre salud pública y protección de datos personales en términos reduccionistas, esgrimiendo una serie de argumentos tautológicos que abogaban por la defensa fervorosa de la salud pública en detrimento de los derechos fundamentales de la privacidad, los cuales, como hemos apuntado, no solo no pueden suspenderse en forma alguna mediante la declaración del Estado de Alarma, sino que constituyen el fundamento mismo del conjunto de derechos constitucionalmente reconocidos ante los crecientes procesos de digitalización y datificación de la sociedad.

En nuestra opinión, no es cierto que la protección de datos personales y su poderosa regulación presidida por el RGPD se presenten como elementos obstruccionistas, 
La necesaria protección de las categorías especiales de datos personales. Una reflexión sobre los datos relativos a la salud como axioma imprescindible para alcanzar el anhelado desarrollo tecnológico frente al COVID-19

conducentes a dificultar la implementación y realización de tratamientos de datos personales necesarios para la adopción de medidas eficaces frente al COVID-19; nada más lejos de la realidad, lo que se persigue, y así lo hemos puesto de manifiesto en las páginas precedentes, es la correcta aplicación de una avanzada regulación de un derecho fundamental, la protección de datos, que recordemos, contempla entre sus disposiciones la realización de actuaciones de tratamiento de datos personales en escenarios atípicos o sobrevenidos como en el que nos encontramos. Por tanto, desde nuestro punto de vista, impregnado quizá por el devenir histórico y el marcado carácter humanista del estudio salmantino es que, el enfrentamiento entre salud pública y protección de datos no es tal, sino más bien todo lo contrario: ambas cuestiones son elementos indisolubles de una misma ecuación. En un contexto de emergencia como el que nos ha tocado vivir es imposible lograr una garantía cierta de la salud pública sin salvaguardar unos elevados estándares de protección de datos personales, derecho este último que como ya hemos insistido, constituye el instituto básico para la plena eficacia y garantía del conjunto de derechos fundamentales reconocidos constitucionalmente, erigiéndose como piedra angular del Estado social y democrático de Derecho ante la ®evolución digital.

Un buen ejemplo de esta necesaria connivencia entre desarrollo tecnológico y salvaguarda del derecho fundamental a la protección de datos de carácter personal lo encontramos en la implementación de la aplicación española Radar COVID, la cual, pese a su tardía puesta en marcha, aspira a ser una herramienta esencial en poder de las autoridades sanitarias para controlar de una vez por todas la propagación y extensión de la pandemia sanitaria. No obstante, conviene precisar que la eficacia y utilidad de la citada aplicación está estrecha y directamente vinculada al uso pleno y responsable por parte de la ciudadanía, cuestión en la que los medios y profesionales de la comunicación adquieren una importancia transcendental, convirtiéndose en agentes indispensables para dotar de información precisa y veraz al conjunto de la población.

\section{REFERENCIAS}

Agencia Española de Protección de Datos (2020). Informe Jurídico 0017/2020, Madrid. Recuperado de https://www.aepd.es/es/documento/2020-0017.pdf

Cotino Hueso, L. (2020). Intelligència artificial, big data i aplicacions contra la Covid-19, i la privacitat i protecció de dades. IDP Revista de Internet, Derecho y Política, (31). doi: $\underline{10.7238 / i d p . v 0 i 31.3244}$

Directiva 95/46/CE del Parlamento Europeo y del Consejo relativa a la protección de las personas físicas en lo que respecta al tratamiento de datos personales y a la libre circulación de estos datos, DOUE § L-1995-81678 (1995). DOUE § L-1995-81678 
La necesaria protección de las categorías especiales de datos personales. Una reflexión sobre los datos relativos a la salud como axioma imprescindible para alcanzar el anhelado desarrollo tecnológico frente al COVID-19

Fernández de Gatta Sánchez, D. (2020). Los problemas de las medidas jurídicas contra el coronavirus: las dudas constitucionales sobre el Estado de Alarma y los excesos normativos. Diario La Ley, (9634). Recuperado de https://diariolaley.laleynext.es/dll/2020/05/18/los-problemas-de-las-medidas-juridicascontra-el-coronavirus-las-dudas-constitucionales-sobre-el-estado-de-alarma-y-losexcesos-normativos

Lozano Cutanda, B. (2020). Análisis de urgencia de las medidas administrativas del estado de alarma. Diario La Ley, (9601). Recuperado de https://diariolaley.laleynext.es/dll/2020/03/25/analisis-de-urgencia-de-las-medidasadministrativas-del-estado-de-alarma

Martínez Martínez, R. (2020a). Los tratamientos de datos personales en la crisis del COVID-19. Un enfoque desde la salud pública. Diario La Ley, 38(1). Recuperado de https://diariolaley.laleynext.es/dll/2020/03/27/los-tratamientos-de-datos-personalesen-la-crisis-del-covid-19-un-enfoque-desde-la-salud-publica

Martínez Martínez, R. (2020b). Covid-19 ¿hacia un rediseño de la privacidad?. La Ley Privacidad, (5). Recuperado de https://diariolaley.laleynext.es/Content/DocumentoRelacionado.aspx?params=H4s|A AAAAAAEAMtMSbF1jTAAAkNTUzMDM7Wy1KLizPw827DM9NS8kIS15JzUxCKXxJJ U58Sc1LyUxCLbkKLSVACVPbJxNwAAAA $==$ WKE

Medina Guerrero, M. (2019). Categorías especiales de datos. En A., Rallo Lombarte (Ed.) Tratado de protección de datos: actualizado con la Ley Orgánica 3/2018, de 5 de diciembre, de Protección de Datos Personales y Garantía de los Derechos Digitales (pp. 251-274). Valencia, España: Tirant lo Blanch.

Ley 33/2011 General de Salud Pública, BOE § A-2011-15623 (2011). ELI: https://www.boe.es/eli/es///2011/10/04/33/con

Ley Orgánica 4/1981 de los estados de alarma, excepción y sitio, BOE § A-1981-12774 (1981). ELI: https://www.boe.es/eli/es/lo/1981/06/01/4/con

Ley Orgánica 3/1986 de Medidas Especiales en Materia de Salud Pública, BOE § A1986-10498 (1986). ELI: https://www.boe.es/eli/es/lo/1986/04/14/3/con

Ley Orgánica 3/2018 de Protección de Datos Personales y Garantía de los Derechos Digitales, BOE § A-2018-16673 (2018). ELI: https://www.boe.es/eli/es/lo/2018/12/05/3

Orden SND/297/2020 por la que se encomienda a la Secretaría de Estado de Digitalización e Inteligencia Artificial, del Ministerio de Asuntos Económicos y Transformación Digital, el desarrollo de diversas actuaciones para la gestión de la crisis sanitaria ocasionada por el COVID-19, BOE § A-2020-4162 (2020). ELI: https://www.boe.es/eli/es/o/2020/03/27/snd297 
La necesaria protección de las categorías especiales de datos personales. Una reflexión sobre los datos relativos a la salud como axioma imprescindible para alcanzar el anhelado desarrollo tecnológico frente al COVID-19

Palacios Cruz, M., Santos, E., Velázquez Cervantes, M. A., y León Juárez, M. (2020). COVID-19, una emergencia de salud pública mundial. Revista Clínica Española, S0014-2565(20), 30092-8. doi: http://doi.org/10.1016/j.rce.2020.03.001.

Piñar Mañas, J.L. (2020a). Privacidad en estado de alarma y normal aplicación de la Ley. Hay Derecho. Recuperado de: https://hayderecho.expansion.com/2020/04/09/privacidad-en-estado-de-alarma-ynormal-aplicacion-de-la-ley/

Piñar Mañas, J.L., (2020b). Los peligros de una república digital desbocada. A propósito del Real Decreto-Ley 14/2019, de 31 de octubre, en materia de administración digital, contratación del sector público y telecomunicaciones. Revista Derecho Digital e Innovación, (3).

Piñar Mañas, J.L., (2020c). Transparencia y protección de datos en el estado de alarma y en la sociedad digital post COVID-19. En D. Blanquer, Covid-19 y Derecho Público (durante el estado de alarma y más allá). Valencia, España: Tirant lo Blanch.

Puente Escobar, A. (2019). Principios y licitud del tratamiento. En A., Rallo Lombarte (Ed.) Tratado de protección de datos: actualizado con la Ley Orgánica 3/2018, de 5 de diciembre, de Protección de Datos Personales y Garantía de los Derechos Digitales (pp. 115-168). Valencia, España: Tirant lo Blanch.

Puyol Montero, J. (2016). Los principios del derecho a la protección de datos. En J.L., Piñar Mañas, M.A., Caro, M., Recio Gayo (Ed.) Reglamento General de Protección de Datos. Hacia un nuevo modelo europeo de privacidad (pp. 135-150). Madrid, España: Editorial Reus.

Real Decreto 463/2020 por el que se declara el estado de alarma para la gestión de la situación de crisis sanitaria ocasionada por el COVID-19, BOE § A-2020-3692 (2020). ELI: https://www.boe.es/eli/es/rd/2020/03/14/463/con

Real Decreto-Ley 6/2020 por el que se adoptan determinadas medidas urgentes en el ámbito económico y para la protección de la salud pública, BOE § A-2020-3434 (2020). ELI: https://www.boe.es/eli/es/rdl/2020/03/10/6/con

Recomendación (UE) 2020/518 de la Comisión Europea de 8 de abril de 2020 relativa a un conjunto de instrumentos comunes de la Unión para la utilización de la tecnología y los datos a fin de combatir y superar la crisis de la COVID-19, en particular por lo que respecta a las aplicaciones móviles y a la utilización de datos de movilidad $\begin{array}{lllll}\text { anonimizados, DOUE } & \text { (2020). } & \text { ELI: }\end{array}$ http://data.europa.eu/eli/reco/2020/518/oj 
La necesaria protección de las categorías especiales de datos personales. Una reflexión sobre los datos relativos a la salud como axioma imprescindible para alcanzar el anhelado desarrollo tecnológico frente al COVID-19

Reglamento (UE) 2016/679 del Parlamento Europeo y del Consejo relativo a la protección de las personas físicas en lo que respecta al tratamiento de datos personales y a la libre circulación de estos datos y por el que se deroga la Directiva 95/46/CE, BOE § A-2020-3434 (2016). ELI: http://data.europa.eu/eli/reg/2016/679/oj

Terrón Santos, D. y Domínguez Álvarez, J.L. (2019). Nueva regulación de la protección de datos y su perspectiva digital. Granada, España: Comares.

Terrón Santos, D., Domínguez Álvarez, J.L. y Fernando Pablo, M.M. (2020). Los derechos fundamentales de la privacidad: derecho y necesidad en tiempos de crisis. Revista General de Derecho Administrativo, (55).

Troncoso Reigada, A. (2010). La protección de datos personales: en busca del equilibrio. Valencia, España: Tirant lo Blanch.

Velavan, T.P., y Meyer, C.G. (2020). The COVID-19 epidemic. Tropical medicine \& international health, 25(3), 278. doi: $10.1111 /$ tmi.13383

\section{AUTOR}

\section{José Luis Domínguez Álvarez}

Joven investigador del Área de Derecho Administrativo de la Universidad de Salamanca. Desde la concesión de la Ayuda para la Formación de Profesorado Universitario (FPU17/01088), y su posterior incorporación a la Universidad de Salamanca en el año 2018 ha centrado su actividad investigadora en torno a tres líneas prioritarias de investigación: protección de datos personales y seguridad de la información, desarrollo rural sostenible e implementación de políticas públicas de igualdad y lucha contra la violencia de género.

Fruto de ello destacan diferentes publicaciones acerca de la nueva regulación en materia de protección de datos personales, la modernización y digitalización de la Administración pública española, la necesidad de reformular las políticas públicas de desarrollo rural sostenible o la importancia de las políticas públicas en la promoción de la igualdad de género.

Orcid ID: https://orcid.org/0000-0002-7623-8029 